\title{
Feasibility of concrete prestressed by shape memory alloy short fibers
}

\author{
K. Moser ${ }^{1}$, A. Bergamini ${ }^{2}$, R. Christen ${ }^{2}$ and C. Czaderski ${ }^{2}$ \\ (1) Henauer Gugler Engineering, Zurich, Switzerland, formerly at (2) \\ (2) Empa, Swiss Federal Laboratories for Materials Testing and Research, Laboratories for Concrete \& Construction \\ Chemistry, Überlandstrasse 129, CH-8600 Dübendorf, Switzerland
}

Received: 2 December 2004; accepted: 28 January 2005

\begin{abstract}
Mortar and concrete exhibit low tensile strengths. Hence, cracks develop easily due to shrinkage and external actions. They can be prevented by applying prestress, thus obtaining crack-free products. Such products exhibit a high bending and tensile strength, are leak proof and of high durability. Prestress can be realized using external or internal wires or cables. In thin walled products, however, this is not feasible. For this purpose, short fibers of shape memory alloy (SMA) wires were embedded in mortar. The wires had been shaped by inelastic elongation into loop- and star-shaped fibers. After hardening of the mortar, the specimens were heated up in order to activate the tensile stress in the fibers, thereby causing a prestress of the surrounding mortar. The effect was monitored by length measurements both on specimens with and without fibers. Compression stresses in the cement mortar were estimated by multiplying the difference in strain between fiber-reinforced and reference prisms by the Young's modulus. Thus, compression of some $7 \mathrm{MPa}$ was reached in the experiments. For practical applications, alloys with suitable temperature domains of austenitic and martensitic transformation, most likely Fe-based, and efficient methods for the production of such fiber mortars are to be developed.

1359-5997 @ 2005 RILEM. All rights reserved.

\section{RÉSUMÉ}

Le mortier et le béton possèdent peu de résistance à la traction et ils se fissurent facilement suite à leur retrait ou sous actions extérieures. Cette fissuration peut être évitée en leur appliquant une précontrainte interne ou externe à l'aide de fils ou de câbles. Les produits précontraints présentent une résistance élevée à la flexion et à la compression; il sont aussi imperméables et possèdent une durabilité élevée. Cette méthode n'est toutefois pas applicable aux éléments de construction de faible épaisseur. Dans la présente étude, des fibres courtes en alliage à mémoire de forme (AMF) ont été noyées dans un mortier. Ces fibres avaient été au préalable formées par élongation inélastique pour leur conférer des formes de boucle et d'étoile. Après durcissement du mortier, les éprouvettes ont été chauffées afin d'activer la contrainte de traction dans les fibres provoquant ainsi une précontrainte du mortier environnant. L'effet des fibres a été déterminé par des mesures de longueur réalisées sur des éprouvettes avec et sans fibres. Les contraintes de compression dans le mortier ont été estimées en multipliant par le module d'élasticité la différence de contrainte entre prismes renforcés de fibres et prismes sans fibres. Des compressions atteignant environs de 7 MPa ont été obtenues dans ces essais. Pour des applicalions pratiques, il sera encore nécessaire de développer des alliages à mémoire de forme (probablement à base de fer) présentant des donaines de température de transformation austénitique et martensitique adéquats et aussi des méthodes efficaces pour la production de tels mortiers.
\end{abstract}

\section{INTRODUCTION}

Concrete and mortar exhibit considerable compressive strengths but very small tensile strengths. Therefore, steel bars are installed in reinforced concrete to resist the tensile forces [1-3]. In thin walled members and for small tension stresses, the use of steel bars is not feasible but fibers can be embedded in the cementitious matrix for the same purpose [4, 5]. In general, these fibers are distributed homogeneously; for respective applications they can be oriented applying special fabrication processes (e.g. by spraying on a mould surface or by extrusion), approaching two directional or nearly one directional orientation of the fibers respectively, thus enhancing their efficiency [6, 7].

Reinforcements (bars or fibers) develop their proper function due to strain, mainly from the onset of cracking of the matrix. Depending on the application, however, such cracks can have detrimental effects on the serviceability state of the element (leakage of pipes, penetration of water through cladding elements, etc.).

To overcome this problem, prestress offers the advantage of mobilizing the strength of the embedded 
tensile members even before cracking. So far, prestress is done by installing wires or strands anchored at the perimeter of the element [3].

To present, shape memory alloys have found very limited applications in civil engineering, probably due to their cost and to the limited knowledge of the material in the building industry. A further disadvantage of the currently used NiTi-alloys is their very low young's modulus.

Applications of SMAs have been the subject of numerous publications. Generally, authors have used straight wires applied to the outside faces of specimens or applied within plastic, metal, mortar or concrete:

Parlinska et al. studied adaptive plastic composites, which are able to change their dynamic properties [8]. Soroushian patented the idea of including shape memory fibers in metal matrices to enhance ductility and energy absorption capacity [9]. Promising applications concentrate on sensing of vibrations, activation of movements in thin walled elements and damping $[10,11]$. A general overview of the properties of SMA as well as an application in adaptive aircraft winglets is given in [12].

In the fields of mortar and concrete, fewer publications can be found. Watanabe et al. used SMA wires generating a compressive residual stress in plaster specimens to achieve higher bending strength [13]. Krstulovic et al. and Maji et al. induced prestress in small plates and beams made of cement-based matrices using SMA wires and strands [14, 15]. Deng et al. prestressed concrete specimens with symmetrically embedded NiTi wires [16]. By using the constrained recovery effect, Soroushian et al. used ironbased SMA wires to transfer corrective forces to a reinforced concrete bridge with beams lacking sufficient shear strength [17].

Furthermore, Krstulovic and Thiedemann used continuous SMA wires as confinement of concrete cylinders to increase the concrete strength and ductility [18] and describe possible combinations of SMA fibers with HPFRC (high-performance fiber reinforced concrete) for fuses for more seismically resistant and cost-effective, autoadaptive frame buildings [19]. Nowadays, tentative applications for SMA in the building industry can be found in the field of seismic retrofit of special buildings (e.g. [20, 21]). Janke et al. give a comprehensive overview on SMA applications in structural engineering [22].

\section{METHOD}

\subsection{Principle}

Metallic fibers embedded in a cementitious matrix and prestressed after hardening of the matrix would enable the production of crack-free thin-walled products with enhanced tensile and bending properties. This process, however, requires fibers, which can be activated while embedded in a hardened mortar or concrete.

Shape memory alloys (SMAs) exhibit remarkable thermo-mechanical properties such as shape memory effect (free recovery effect), pseudo elasticity, changing of the mechanical properties due to temperature and stress changes as well as the constraint recovery effect. The latter is used in this project: SMA fibers tensioned into their inelastic domain and heated up, tend to contract to their initial length thus developing tension stresses. For fibers embedded in mortar, this contraction is constrained by the surrounding matrix and a compression i.e. prestressing of the mortar should result.

The required ideal properties of SMAs for this application can be defined as follows: in Fig. 1 the typical phase changes of thermo elastic SMAs are shown in an idealized form for the martensitic phase fraction in function of the temperature. Stable conditions are encountered below $A_{s}$ for the martensitic phase and above $M_{s}$ for the austenite phase (service temperature ranges without phase change). The pre-deformation of SMA fibers should be carried out in the martensite. During the installation of the fibers into concrete and subsequent hardening of concrete, the SMA fibers must stay in the martensitic state without transforming into the austenite. Therefore, $A_{s}$ should be higher than the temperatures to which the SMAs are subjected through the concrete hardening process. After hardening of the concrete matrix, the concrete elements including SMA fibers are heated ideally above $A_{f}$ in order to induce a full austenitic transformation and to produce the corresponding maximum shape recovery stress. Thus, the temperature $\AA_{f}$ should be lower than the temperature where the degradation of concrete starts. For cementitious materials, this temperature should not exceed approximately $95^{\circ} \mathrm{C}$ in order to avoid thermally induced micro cracking in the mortar matrix.

For sinking temperature thereafter, the phase transforms to martensite for temperatures between $M_{s}$ and $M_{f}$. For outdoor applications, service temperatures in moderate climates can be as low as $-25^{\circ} \mathrm{C}$. Thus, the upward transformation domain $\left(A_{s}\right.$ to $A_{f}$ ) should lie in between $60^{\circ} \mathrm{C}$ and $95^{\circ} \mathrm{C}$ due to constraints set by the production process, whereas $M_{s}$ should be below $-25^{\circ} \mathrm{C}$ due to service temperature requirements.

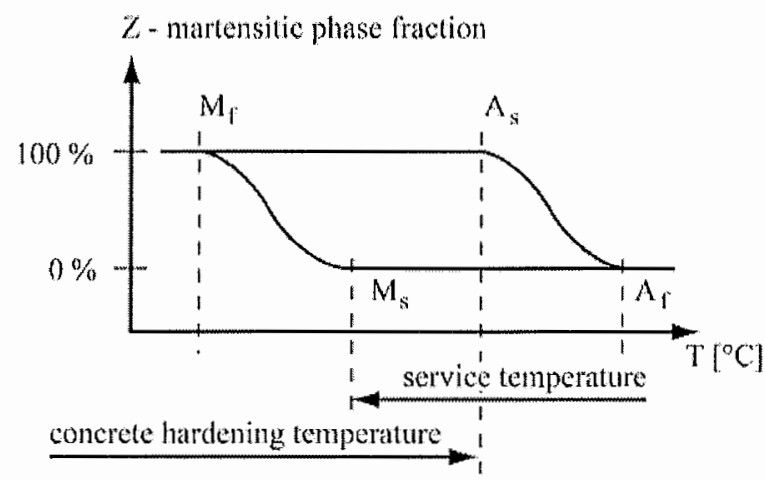

$\mathrm{M}_{\mathrm{s}}: \quad$ Start of martensitic phase transformation

$M_{f}$ : Finish of martensitic phase transfomation

$A_{s}:$ Stat of austenitic phase transformation

$A_{f}$ : Finish of austenitic phase transformation

Fig. 1 - Phase transformation of shape memory alloys. 


\subsection{Procedure}

The goal of this feasibility study was to show that cementitious mortars or concretes can be prestressed using short SMA fibers. For this purpose, mortar prisms were produced both with and without such fibers. The specimens were heated up in order to activate the SMA-fibers. Prestress (compression stress) results in a shortening of the specimens, therefore the lengths of the prisms were monitored throughout the experiments. The differences between the prisms containing fibers and the reference prisms are considered to be caused mainly by prestress due to the SMA fibers.

\subsection{SMA Wire}

A shape memory alloy available on the market was used (NiTi-Alloy, wire diameter $0.25 \mathrm{~mm}$ ). According to the information given by the supplier, this alloy is in the martensitic phase at room temperature and has a transformation temperature $A_{f}$ (austenite finish) of approximately $65^{\circ} \mathrm{C}$.

In order to obtain more detailed information about the phase transformation temperatures, a differential scanning calorimeter measurement (DSC) was performed, resulting in the transformation temperatures shown in Table 1.

Without restraint, it can be expected, that heating up to $95^{\circ} \mathrm{C}>65^{\circ} \mathrm{C}$ reverses the entire pre-elongation. However, if the deformation is restrained, heating produces a tensile stress in the alloy. It is known that in restraint conditions, the temperatures are shifted upwards and thus the effect at a given temperature will be reduced [23, 24]. After cooling this alloy down to $20^{\circ} \mathrm{C}$, practically the entire prestress will be lost again due the transformation back into the martensitic state.

Fig. 2 shows the deformation behaviour of a SMA wire specimen at room temperature. The wire of $100 \mathrm{~mm}$ free length was clamped at both ends, pulled to $10 \%$ elongation and relieved. The horizontal section of the curve with the strain domain of about $5 \%$ is due to the predominant reorientation (detwinning) of the martensite. This plateau region is followed by a sharp increase in stress due to elasto-plastic deformation of fully oriented martensite. Wire diameter after pre-deformation was $0.24 \mathrm{~mm}$. When the wire is heated above $A_{f}$ without constraint, a major part of the residual stress is recovered. The high pre-deformation of $10 \%$ was chosen to give a respective high recovery stress for this onetime application.

On the other hand, if the wire is heated under constraint, a tensile stress is produced in the wires, causing pre-stress in the matrix. In order to determine the effective recovery stresses due to different temperatures, the pre-deformed wires were subjected to temperature cycles with both ends clamped. The force acting on the restraint was measured and is shown in Fig. 3 as stress versus temperature.

The results show that in the cycle numbers 1 to 3 , performed on one specimen, stresses of 185, 230 and $405 \mathrm{MPa}$ are attained at temperatures of 90,100 and $120^{\circ} \mathrm{C}$. The large cycle number 4 performed on a second specimen results in a stress of $845 \mathrm{MPa}$ at $180^{\circ} \mathrm{C}$. The large cycle

\begin{tabular}{|l|c|c|}
\hline $\begin{array}{c}\text { Table 1 - Approximate transformation temperatures } \\
\text { of NiTi - Alloy wire used }\end{array}$ \\
\hline Transformation & Symbol & $\mathrm{T}\left[{ }^{\circ} \mathrm{C}\right]$ \\
\hline start of austenitic transformation & $\mathrm{A}_{\mathrm{s}}$ & 58 \\
finish of austenitic transformation & $\mathrm{A}_{\mathrm{f}}$ & 70 \\
start of martensitic transformation & $\mathrm{M}_{\mathrm{s}}$ & 55 \\
finish of martensitic transformation & $\mathrm{M}_{\mathrm{f}}$ & 47 \\
\hline
\end{tabular}

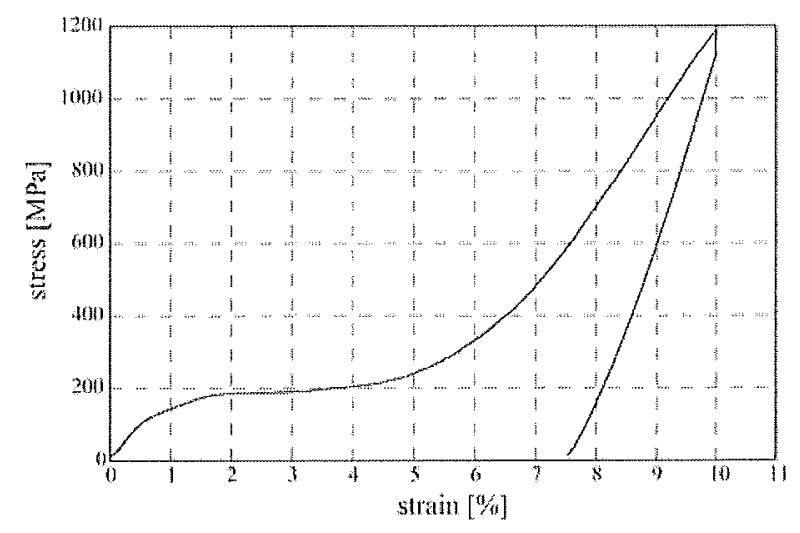

Fig. 2 - Stress-strain behaviour of SMA wire during predeformation to $10 \%$ strain.

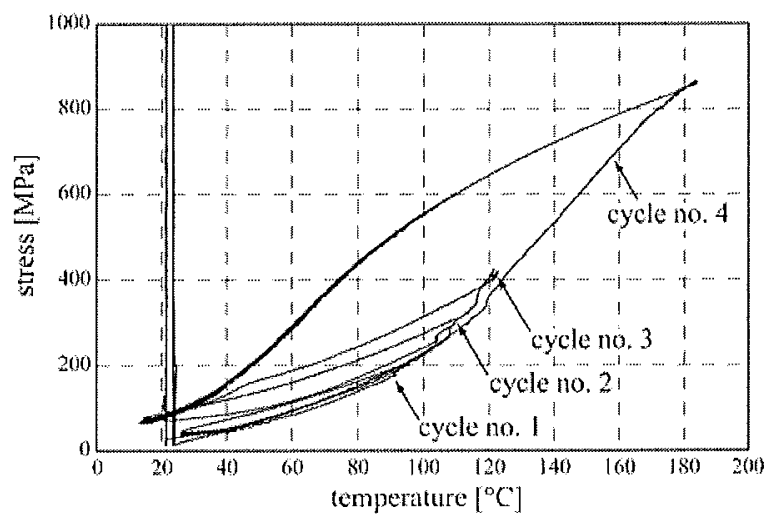

Fig. 3- Stress in SMA wire due to temperature cycles under restrained conditions.

transformation curve represents the envelope of the partial cycles. The shape of the curve indicates that the plateau has not been reached yet and that increasing temperature further would lead to respective higher stresses.

\subsection{Preparation of SMA short fibers}

Anchorage of wires by friction alone results in small fiber stresses only. Friction can be improved to some degree by treating the surface of the wires, but effective transmission of forces is only given by geometrical anchorage. Due to the production process of the alloy, however, shapes as they are common with steel fibers (e.g. end hooks), cannot be fabricated easily, and due to the relatively low Young's modulus cannot be very efficient. 
The development of a suitable form of anchorage was judged crucial. A new form of fiber was therefore developed and tested. The so-called loop or star-fibers are based on geometrical anchorage. The fibers were produced in two steps (see Fig. 4a):

1. The annealed wire coil was put onto a stretching device in sections (see Fig. 5) and was inelastically elongated to the amount required (here 10\%). After release, the coils showed an elliptical shape of a length of $36 \mathrm{~mm}$ to $38 \mathrm{~mm}$.

2. From this elliptical coil, loop-fibers were cut (see Figs. $4 \mathrm{a} \&$ b). The friction on the relatively long bent ends of the wire effects anchorage.

For the purpose of these experiments, two loop fibers mostly were left together, resulting in star-shaped fibers as shown in Fig. 4c. The star-fiber's length is double the length of a loop-fiber. One anchorage serves in effect 2.5 connected loop fibers, thus enhancing the efficiency of the wire material used.

\subsection{Mortar}

A standard cement mortar according to EN 196-1 was used, consisting of $2.7 \mathrm{~kg}$ EN-standard sand (max. grain size $2 \mathrm{~mm}$ ), $900 \mathrm{~g}$ cement CEM I $42.5 \mathrm{~N}$ and $450 \mathrm{~g}$ water ( $\mathrm{w} / \mathrm{c}-$ ratio $=$ $0.50)$. Characteristic strengths were tested on standard prisms of $40 \mathrm{~mm} \times 40 \mathrm{~mm} \times 160 \mathrm{~mm}$ after curing under water for 28 days. The compression strength was $45 \mathrm{MPa}$, the bending tensile strength 7.2 $\mathrm{MPa}$. The elastic (Young's) modulus measured on these prisins was $30.8 \mathrm{GPa}$ at 28 days before and on the large prisms $80 \mathrm{~mm} \times 80 \mathrm{~mm} \times 320 \mathrm{~mm} 27.9 \mathrm{GPa}$ $(91 \%)$ at 110 days after the three temperature cycles.
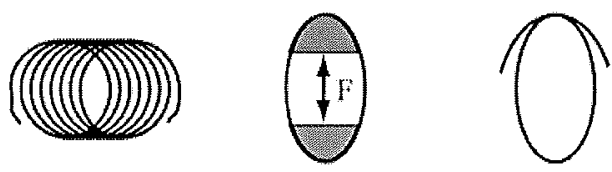

a) schematic procedure
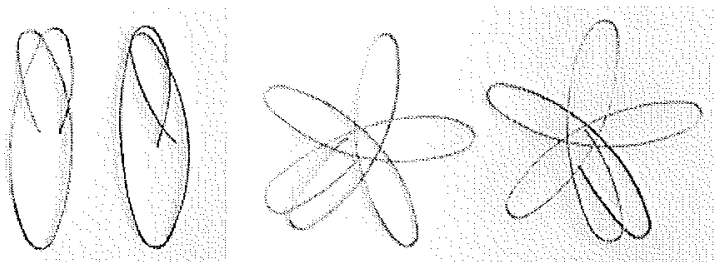

b) loop-fibers

c) star-fibers

Fig. 4 - Production of loop- and star-fibers from annealed wire coils.

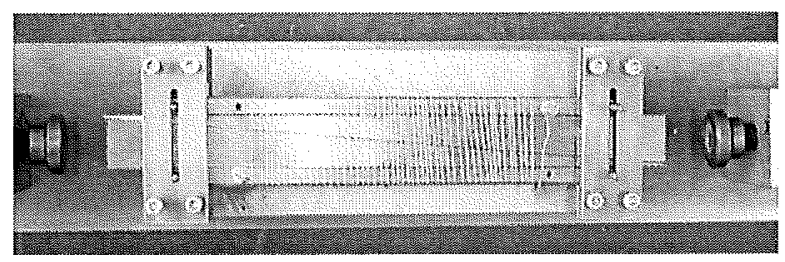

Fig. 5 - Stretching device.

\subsection{Production of SMA short fiber mortar prisms}

Two large mortar prisms of $80 \mathrm{~mm} \times 80 \mathrm{~mm} \times 320 \mathrm{~mm}$ were produced without fibers (denoted $\mathrm{R}$ for reference) and two with fibers (denoted $\mathrm{F}$ for fiber). The mortar was placed in five layers, alternatively with four layers of the star-shaped fibers and some loop fibers (see Fig. 6), and compacted on a vibration table. The total fiber content was $1.2 \%$ by volume. Bolts for periodic length measurements were glued on the four long sides of the prisms at the age of one day (Deformeter Ditast, measurement length $250 \mathrm{~mm}$, see Fig. 8). The prisms were cured under water at $20^{\circ} \mathrm{C}$ for 28 days.

\subsection{Experimental procedure}

After the hardening of the mortar, the samples were heated up in steps, causing the transformation of the SMA wires from the martensitic into the austenitic phase, thus prestressing the matrix. The following temperature cycles were performed (see Fig. 7):

1. First cycle up to $T_{\max }=90^{\circ} \mathrm{C}$ with specimens R1 \& F1 submerged in water.

2. Second and third cycles up to $100^{\circ} \mathrm{C}$ and $120^{\circ} \mathrm{C}$ respectively, with all specimens in air (free evaporation of water in open containers, to reduce drying of specimens).

3. Fourth cycle (R1 \& F1 only) up to $180^{\circ} \mathrm{C}$ in dry air (no evaporation of water in oven).

Temperatures were monitored in the centre point and at the surface of one mortar prism as well as in the air of the oven using K-type thermocouples.

Heating the specimen submerged in water for the first cycle required 54 hours up to a temperature of $89^{\circ} \mathrm{C}$, resulting in a temperature cycle of 5 days. The following cycles were done in air and heating achieved about $20 \mathrm{~K}$ temperature rise within 3 hours in the centre of the specimens.

\section{RESULTS}

\subsection{Strains of mortar prisms}

For the strain measurements, the specimens were removed from the oven for some minutes at steps of $20 \mathrm{~K}$.

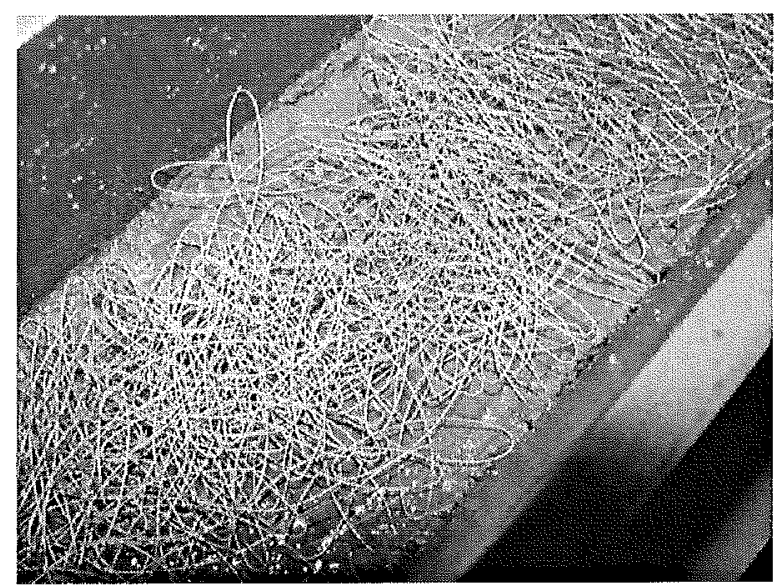

Fig. 6 - Typical fiber layer. 


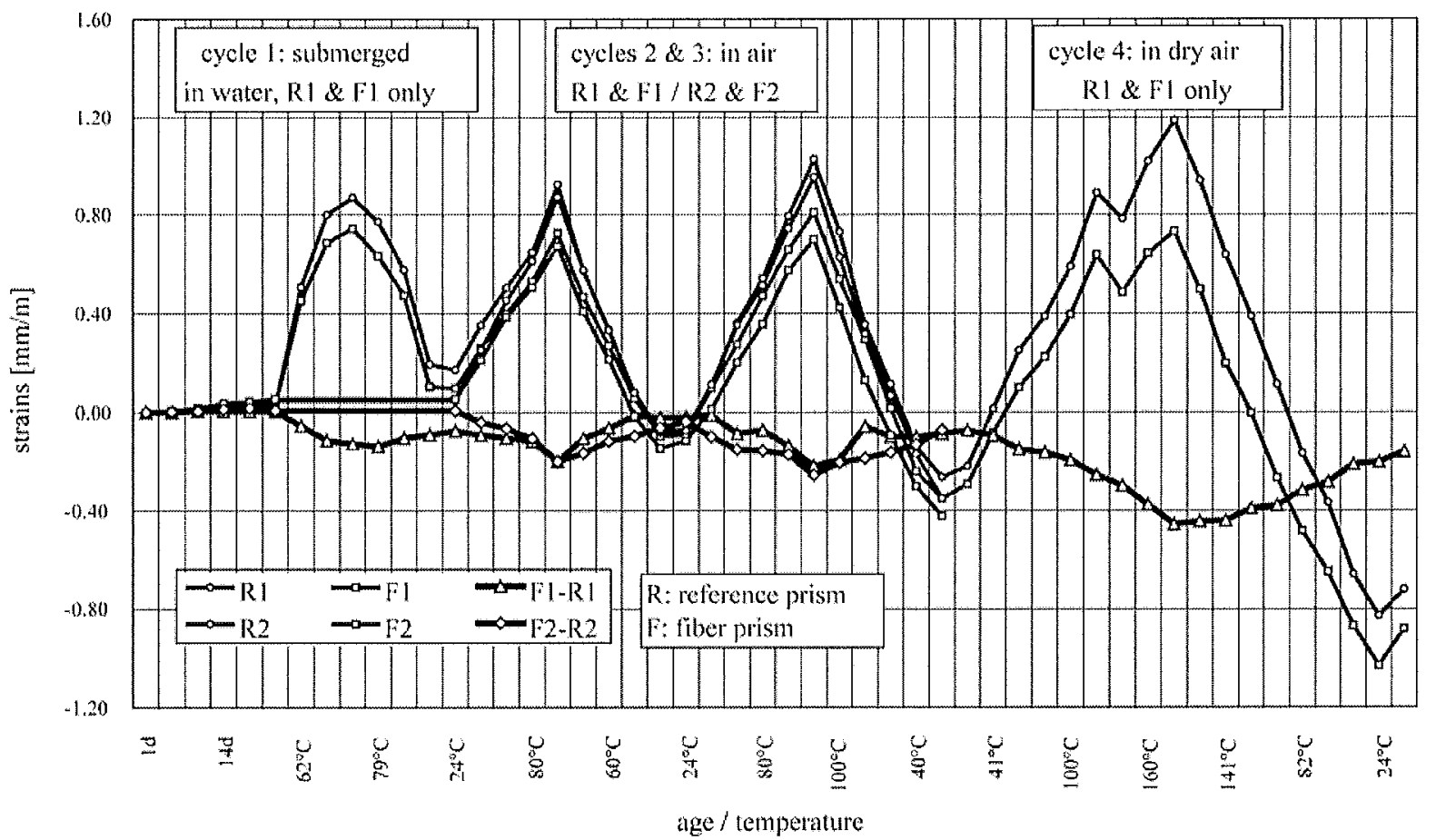

Fig. 7 - Strains of mortar prisms during temperature cycles.

The surface temperature of the specimen dropped 3 to $10 \mathrm{~K}$ depending on the temperature level and the speed of measurement while the temperature in the centre of the prism remained unaffected.

Strains $\varepsilon_{c}=\Delta l / l$ of reference prisms (denoted R) and fiber prisms (denoted $F$ ) are plotted against age up to 28 days and against temperature thereafter (Fig. 7). Average values of the four sides were used (for method of measurement see Fig. 8). The differences in strains between reference prisms and fiber prisms (F1-R1 and F2-R2) are also shown for both pairs of prisms.

The first cycle immersed in water was done with one pair of prisms only. After this cycle in water, a small residual elongation of both specimens can be observed.

The following two cycles in air were performed with all four specimens. It can be seen from Fig. 7, that a slight shortening of the specimens took place in each cycle, indicated by negative strains for both fiber and reference specimens. The fourth cycle in dry air exhibited the largest shortening.

\subsection{Residual stresses in mortar}

After all temperature cycles, each large prism was cut into 8 small prisins about $40 \mathrm{~mm} \times 40 \mathrm{~mm} \times 150 \mathrm{~mm}$ and tested at room temperature. Four of these small prisms were tested in tension. Notches were cut at mid-length on opposite sides to define the location of the crack. Four further prisms were tested in three-point bending (span $100 \mathrm{~mm}$, see Fig. 9).

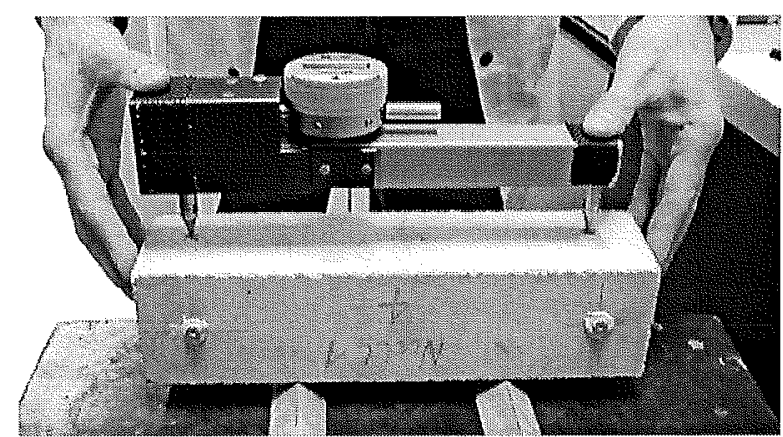

Fig. 8 - Strain measurement on prism $80 \times 80 \times 320 \mathrm{~mm}$.

\begin{tabular}{|c|c|c|c|c||c|c|}
\hline \multicolumn{7}{|c|}{ Table 2 - Resistance to tension and bending and } \\
corresponding residual stresses \\
\hline prism & $\begin{array}{c}\text { age } \\
{[\mathrm{d}]}\end{array}$ & $\begin{array}{c}T_{\max } \\
{\left[{ }^{\circ} \mathrm{C}\right]}\end{array}$ & $\begin{array}{c}f_{i} \\
{[\mathrm{MPa}]}\end{array}$ & $\begin{array}{c}\Delta f_{t} \\
{[\mathrm{MPa}]}\end{array}$ & $\begin{array}{c}f_{b t} \\
{[\mathrm{MPa}]}\end{array}$ & $\begin{array}{c}\Delta f_{b t} \\
{[\mathrm{MPa}]}\end{array}$ \\
\hline \hline R1 & 120 & 180 & $\begin{array}{c}2.5 \\
\text { F1 }\end{array}$ & 1.3 & 6.0 & 1.2 \\
\hline R2 & \multirow{2}{*}{91} & 120 & $\begin{array}{c}2.3 * \\
\text { F2 }\end{array}$ & 1.6 & 6.9 & 1.2 \\
\hline
\end{tabular}

Remark: * three results only

The mean values of the tensile strengths $f_{l}$ and bending tensile strength $f_{b t}$ at the formation of the first cracks and the respective differences between reference and fiber prisms $\Delta f=f(\mathrm{~F})-f(\mathrm{R})$ are shown in Table 2. 

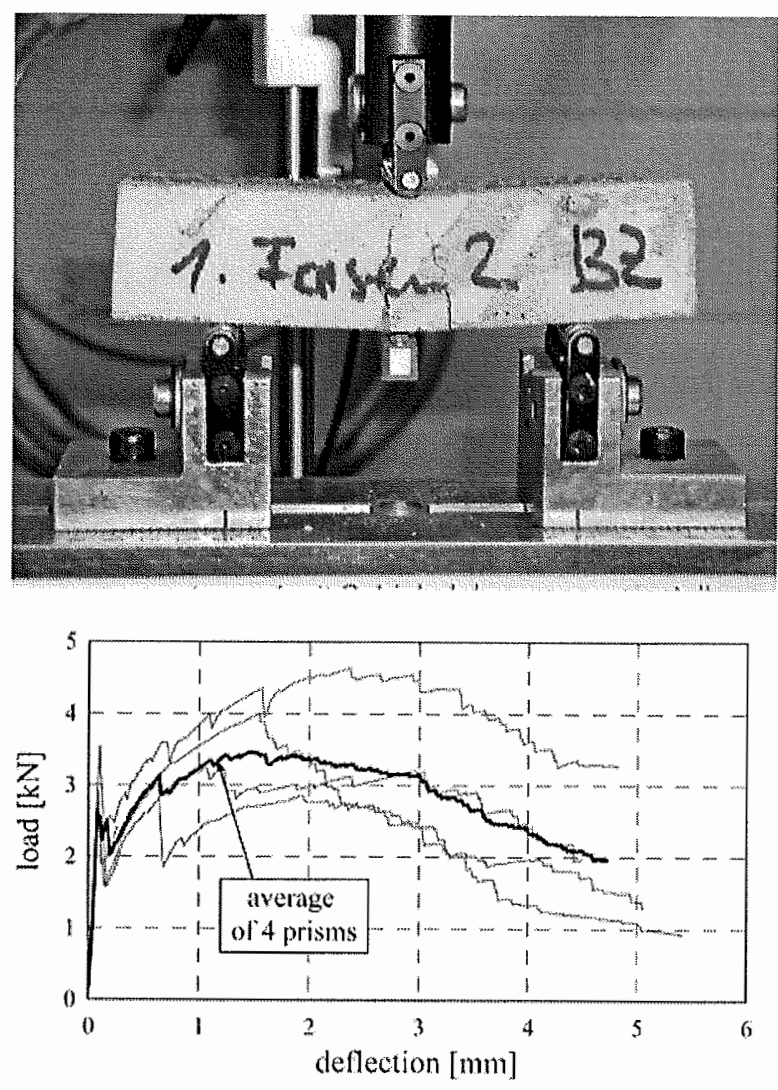

Fig. 9 - Bending resistance of prisms cut from F1 (load versus deformation, $\mathrm{L}=100 \mathrm{~mm}$ ).

\section{DISCUSSION}

\subsection{Strains during temperature cycles}

The general variation in length over the temperature cycles is due to temperature variation. A difference in temperature of $70 \mathrm{~K}$ resulted in an elongation of $0.80 \mathrm{~mm} / \mathrm{m}$ (see Fig. 7). This corresponds to a coefficient of thermal expansion of $\alpha \approx 1.1510^{-5} / \mathrm{K}$, quite common for a mortar consisting of quartz sand.

The strain versus temperature behaviour during the first cycle exhibits a more rounded shape than the consecutive cycles. This cycle lasted 5 days, whereas the consecutive cycles in air took only 2 to 3 days to complete.

After the first cycle, a residual positive strain was observed for both specimens. This "strain" is interpreted as an elongation of the prisms submerged in water due to swelling.

After the cycles in air, residual shortening can be observed to increase with higher peak temperature. The shortening of the reference prisms can be attributed to the effects of shrinkage. The difference between reference and fiber prisms is considered to be due to the effect of the fibers. The slight recovery at the end of the series was caused by the storage at $20^{\circ} \mathrm{C}$ and $50 \%$ relative humidity for four days (swelling).

\subsection{Tensile and bending tests}

At ambient temperature between and after the experiment, some difference in length and hence "strain" appear to be residual. This can be attributed to two effects:

1. The SMA alloy does not recover fully after the temperature cycles and a residual stress remains in the specimens at room temperature (see Fig. 3 at $T=20^{\circ} \mathrm{C}$ ).

2. Creep due to prestress does manifest as shortening, but no corresponding stress develops in a freely deforming body.

The fiber prisms exhibit higher strengths in tension and in bending at the first crack than the reference prisms. Differences of 1.3 MPa and 1.2 MPa result (Table 2).

The behaviour in bending in the post-cracking state is very ductile. In the test, the average resistance rises to a maximum resistance of $3.4 \mathrm{kN}$ at a displacement of $1.5 \mathrm{~mm}$, exceeding the resistance at cracking of $2.6 \mathrm{kN}$ by $30 \%$ (Fig. 9).

\subsection{Estimation of prestress in mortar}

The prestress of the mortar depends on the stress in the fibers on one hand and on the content and on the distribution of the fibers on the other hand. The effectiveness of fibers with regard to a specific direction is widely discussed in literature using various models (e.g. $[25,26])$. In the specimens of this study, the fibers were randomly distributed in parallel planes in the cement mortar (layers). According to [26] for a random distribution in two directions, a factor of $2 / \pi$ applies for the fraction of fibers crossing a potential crack. This leads to the following equation for the prestress in the mortar:

$\sigma_{c}=p \cdot \sigma_{p} \cdot 2 / \pi$

where: $\quad \sigma_{c}:$ compression stress in mortar

$p:$ content of fibers (per volume)

$\sigma_{p}:$ tension stress in fibers

In the experiments, a fiber content of $p=1.2 \%$ by volume was used. The estimated mortar stresses based on the stresses in the fibers, determined in single wire tests in section 2.3, are shown in Table 3.

\begin{tabular}{|c|c|c|}
\hline \multicolumn{3}{|c|}{ Table 3 - Tensile stress in SMA fibers and } \\
estimated prestress in cement mortar for various \\
activation temperatures (Equation (1))
\end{tabular}

\subsection{Prestress assessed from measured strains}

For the purpose of quantification, the difference in length between reference prisms and fiber prisms 
(shortening) is considered to be caused by the internal prestress $\sigma_{c}$. Effects such as temperature and shrinkage are assumed to be identical in both prisms. Generally, stresses $\Delta \sigma_{c}$ can be calculated from the differences in strain measured $\Delta \varepsilon_{c}$ using Hook's law:

$\Delta \sigma_{c}=\Delta \varepsilon_{c} \cdot E_{c}$

The elastic modulus $E_{c}$ of the mortar was determined at 28 days as $30.8 \mathrm{GPa}$ and at the end of the experiments as $27.9 \mathrm{GPa}$. The smaller value after the experiments is considered to be the result of micro cracks in the mortar, induced by the exposure to temperatures above $100^{\circ} \mathrm{C}$.

For the purpose of this feasibility study, stresses are calculated using the difference in strain between the average value before and after each cycle and the maximum value at the peak temperature of the cycle. The resulting values should be free of the effects of shrinkage and the influence of creep on the estimation is minimised.

Compression stresses (prestress) in the mortar reached values between 2.5 and $8.9 \mathrm{MPa}$ at maximum temperatures. These stresses derived at from the strain measurements, are larger than the values from Table 3, estimated using a model for the random distribution of the fibers in two directions (parallel planes).

This discrepancy could at least partially be attributed to creep of the prestressed prisms. Creep causes shortening, but without stress. In the stress estimation, however, the entire shortening during a cycle is attributed to compressive stresses.

The effects of creep are not easy to quantify. Assuming an average stress of $1 \mathrm{MPa}$ over the entire period of the tests and a creep value of $\varphi \approx 1.9$, a difference in length equalling to a "strain" of $0.10 \%$ results:

$\varepsilon \approx(1.0 \mathrm{MPa} / 27.9 \mathrm{GPa})(1+\varphi)=0.10 \%$.

Using the last "strain" measurement at 105 days and taking into account this amount of creep, the following residual stress results:

$\sigma \approx(0.161 \%$ - $0.10 \%$ o $) 27.9 \mathrm{GPa}=1.7 \mathrm{MPa}$.

The residual stresses derived at from the mechanical tests at the end of the experiment are somewhat lower: 1.2 and 1.3 MPa, but of the same order (see Table 2). The effective maximum prestress reached is therefore estimated to be of the order of $7 \mathrm{MPa}$.

A reliable isolation of the creep effects during the entire experiment would require additional data to be gathered in further experiments.

\section{CONCLUSIONS}

1. The experiment shows, that prestressing of mortars using SMA short fibers activated after hardening of the mortar is feasible. Substantial prestress up to about $7 \mathrm{MPa}$ was attained in the experiments.

2. As the transformation domain of the alloy used shifts considerably under restrained conditions, a temperature of $180^{\circ} \mathrm{C}$ was required to reach a stress of $845 \mathrm{MPa}$ in the fibers.
3. The relatively high temperatures during cycles 3 and 4 , however, did not cause much interior damage to the mortar (micro cracking) as the elastic modulus was only reduced by about $10 \%$.

4. The SMA used transformed back to the martensitic phase for the most part when cooling down to room temperature and therefore corresponding residual stresses were small (see Fig. 3 \& Table 2).

5. In order to attain crack-free mortar products, a prestress of the order of a few MPa can be applied to overcome the cracking due to shrinkage. Mortar products subjected to bending and tension due to external actions might require a somewhat higher prestress. The experiments showed that a high level of prestress can be attained (patent pending [27]).

\section{OUTLOOK}

While the feasibility has been shown, substantial development steps are necessary towards practical application, requiring research in the following areas:

1. For industrial and building applications suitable alloys have to be developed to suit the production and service temperatures envisaged.

2. The cost of the alloy has to be considerably lower. Febased SMA alloys may prove to be less costly and well suited for applications in cement-based mortars.

3. The optimum parameters such as fiber diameter, fiber content, fiber shape, etc. have to be investigated.

4. Means of mixing or spraying fibers into the mortar have to be developed for efficient production.

5. Other means of activating the SMA fibers such as induction heating can have considerable potentials in industrial application and have to be investigated.

6. Long-term behaviour of the prestressed mortar has to be analysed and tested (creep, durability, etc.).

The technique of embedding short SMA fibers in cement based mortar or in concrete and activating after hardening of the matrix, bears a great potential for the production of internally prestressed crack free industrial and building products.

\section{ACKNOWLEDGEMENTS}

This feasibility study was funded by internal means of Empa. The support of the director's board is gratefully acknowledged.

\section{REFERENCES}

[1] Mörsch, E., 'Reinforced concrete (Der Eisenbetonbau)' (Stuttgart, 1923) [only available in German].

[2] Leonhard, F., 'Lectures on Reinforced Concrete Construction Part 1: Design Principles (Vorlesungen über Massivbau - Teil 1: Grundlagen zur Bemessung im Stahlbetonbau)' (Berlin New York: Springer, 1984) [only available in German].

[3] Hampe, E., Raue, E. and Kaller, W., 'Reinforced Concrete Part 1: Basic Principles' (Stahlbeton - Teil 1: Grundlagen) 
(Berlin - München: Verlag für Bauwesen, 1993) 304 [only available in German].

[4] Bentur, A. and Mindess, S., 'Fiber Reinforced Cementitious Composites' (London - New York: Elsevier Applied Science, 1990).

[5] König, G., Holschemacher, K. and Deln, F., 'Fiber Reinforced Concrete (Faserbeton)' (Berlin: Bauwerk Verlag GmbH., 2002) 320 [only available in German].

[6] Hesselbartl, D. and Kaufmann, J., 'High Strength Fiber Reinforced Composite (Hochleistungsfaserkomposit)', Swiss Federal Institute for Materials Testing and Research (Empa): Dübendorf, section 4.8.1, 2004 [only available in German].

[7] Shao, Y. and Shah, S.P., 'Mechanical properties of PVA fiber' reinforced composites fabricated by extrusion processing', ACI Materials Journal 94(6) (1997) 555-564.

[8] Parlinska, M., et al., 'Adaptive composites with embedded shape memory alloys. Journal de Physique IV, France, (11) (2001) 197-204.

[9] Soroushian, P., 'Metal matrix materials reinforced with shape memory fibers for enhanced ductility and energy absorption capacity, and method of manufacturing same', United States Patent No. 6,025,080, February 15, 2000.

[10] Chung, D.D.L., 'Cement Matrix Composites for Smart Structures', Smart Mater. Struct., 2000(9): p. 389-401.

[11] Chen, S.H., G.F. Yao, and C. Huang, A New Intelligent ThinShell Element. Smart Mater. Struct., 2000(9): p. 10-18.

[12] Balta Neumann, J.A., 'Adaptive composites with embedded shape memory alloy wires', in Faculté Sciences et Techniques de l'Ingénieur, Ecole Polytechnique Fédérale de Lausanne (EPFL): Lausanne (2003) 175.

[13] Watanabe, Y., Miyazaki, E. and Okada, H., 'Enhanced mechanical properties of $\mathrm{Fe}-\mathrm{Mn}-\mathrm{Si}-\mathrm{Cr}$ shape memory fiber/plaster', Smart Composite. Materials Transactions 43(5) (2002) 974-983.

[14] Krstulovic-Opara, N. and Naaman, A.E., 'Self-stressing fiber composites', ACI Structural Journal 97(2) (2000) 335-344.

[15] Maji, A.K. and Negret, I., 'Smart prestressing with shapememory alloy', Journal of Engineering Mechanics-ASCE 124(10) (1998) 1121-1128.

[16] Deng, Z., et al., 'Behavior of concrete driven by uniaxialy embedded shape memory alloy actuators', Journal of Engineering Mechanics-ASCE 129(6) (2003) 697-703.
[17] Soroushian, P., et al., 'Repair and strengthening of concrete structures through application of corrective post tensioning forces with shape memory alloys', in 'Design of Structures' (Transportation Research Board Natl. Research Council: Washington, 2001) 20-26.

[18] Krstulovic-Opara, N. and Thiedemann, P.D., 'Active confinement of concrete members with self-stressing composites', ACI Materials Journal 97(3) (2000) 297-308.

[19] Krstulovic-Opara, N., et al., 'Self-actuating SMA-HPFRC fuses for auto-adaptive composite structures', Computer-Aided Civil and Infrastructure Engineering 18(1) (2003) 78-94.

[20] Magonette, G., 'Shape memory alloys RF in civil engineering with particular regard to old structures', in 'Shape Memory Alloys. Advances in Modelling and Applications', (Iuternational Centre for Numerical Methods on Engineering (CIMNE), Barcelona, Spain, 2001).

[21] Saadat, S. et al., "An overview of vibration and seismic applications of NiTi shape memory alloy', Smart Mater. Struct. (11) (2002) 218-229.

[22] Janke, L., Czaderski, C., Motavalli, M. and Ruth, J., 'Applications of Shape Memory Alloys in Civil Engineering Structures - Overview, Limits and New Ideas', Maier. Siruct. 38 (279) (2005) 578-592.

[23] Duerig, T.W., 'Engineering Aspects of Shape Memory Alloys' (London etc.: Butterworth-Heinemann. XI, 1990) 499.

[24] Shrinivasan, A.V. and McFarland, D.M., 'Smart Structures' (Cambridge: Cambridge University Press, 2001).

[25] Yong-zhi, L., 'Behaviour of Fiber Reinforced Concrete under Load (Tragverhalten von Stahlfaserbeton)', Heft 494 (Deutscher Ausschuss für Stahlbeton: Berlin, 1999) [only available in German].

[26] Pfyl, T., 'Behaviour of Fiber Reinforced Concrete under Load (Tragverhalten von Stahlfaserbeton)', Swiss Federal Institute of Technology (ETH): Zurich, 2002, 140 [only available in German].

[27] Bergamini, A, Moser, K., Christen, R. and Czaderki, C., 'Internally prestressed cementitious building material, and method of manufacturing same (Innerlich vorgespannter zementgebundener Baustoff und Verfahren $\mathrm{zu}$ seiner Herstellung, Swiss patent No. 01935/04, pending, November 24, 2004 [only available in German]. 